\title{
Nursing Informatics Competency After Experiencing Simulated Electronic Health Records: Descriptive Study
}

\author{
Jeeyae CHOI, RN, PhD ${ }^{\mathrm{a}, 1}$, Lisa BOVE, RN, DNP ${ }^{\mathrm{a}}$ and Valerie TARTE, RN, DNPa \\ ${ }^{a}$ School of Nursing, University of North Carolina Wilmington, \\ Wilmington, North Carolina, USA
}

\begin{abstract}
Nursing has embraced flexible online advanced education as a means of increasing the supply of nurse professionals. Virtual simulation and other adaptive learning technologies enhance learning efficiency and student outcomes. A simulated electronic health record (DocuCare) was adopted in an online graduate nursing informatics course. An assignment using DocuCare to learn core concepts of nursing informatics was developed for graduate students enrolled in a nursing informatics course. A validated standard informatics survey instrument was used to measure three individual domains (basic computer skills, roles, and advanced computer skills (clinical informatics)) as well as the combined informatics competency level. Overall, the nursing informatics competency level was between competent and proficient; basic computer skills and roles were above proficient; and advanced computer skills (clinical informatics) fell between competence and proficient levels.
\end{abstract}

Keywords. Virtual simulation, electronic health records, nursing informatics, online learning

\section{Introduction}

Nationwide, a nursing faculty shortage and physical space constraints limit enrollment to brick and mortar nursing programs. To overcome these barriers, nursing has embraced online education. Advances in information and communication technology have made high quality online courses possible and provide a versatile learning environment $[1,2]$. Nursing faculty continuously endeavor to enhance learning using adaptive learning technologies so students can apply knowledge acquired in practice $[3,4]$.

Virtual simulation and an adaptive learning technology have been used to increase student-learning efficiency in online nursing courses $[5,6]$. Online learning focuses on individual students, is flexible in time and place, enhances knowledge through easy access to information, and facilitates interaction through discussion forums and collaboration. However, critics claim it is merely a delivery mechanism for existing methods of learning, lacks personal interactions and community, and is ineffective when

${ }^{1}$ Corresponding Author, Jeeyae Choi, Associate Professor, University of North Carolina Wilmington, School of Nursing, 602 S. College Road, McNeill Hall, Rm 2049, Wilmington, NC 28403, USA; E-mail: choij@uncw.edu. 
hands-on practical skills need to be learned [7]. To counter these criticisms and maximize learning efficiency, virtual simulation has been integrated within nursing curricula.

Health Care Systems and Education Informatics and Technology is a graduate online nursing informatics course for a family nurse practitioners program. This is the first informatics course ever developed at the School of Nursing in a University, North Carolina. While the course has been well received, concern exists that students struggle to apply sophisticated and complex informatics concepts and knowledge in practice. A simulated hands-on learning experience blended in the course might facilitate student application of informatics knowledge in practice was an underlying motivation of this study.

Electronic Health Records (EHRs) have become the major source of patient information and documentation in health care. With expanding use of EHRs, the integrity and quality of data and information input for sharing among clinicians becomes important. Some suggest EHR education and training should be taught in graduate informatics courses [8].

The purpose of this study was to assess nursing informatics competency levels after completing simulated electronic health records as an assignment in an online graduate informatics course. Descriptive analysis was performed on survey data gathered from students completing the Self-Assessment of Informatics Competency Scale for Health Professionals (SICS) [9].

\section{Methods}

\subsection{Study Design}

Quantitative, descriptive research design was used to assess nursing informatics competency level.

\subsection{Study Setting}

DocuCare is a simulated EHR developed for academic use. It allows students to learn how patient data and information are constructed and encourages critical thinking about patient documentation using patient scenarios in a safe and true-to-life setting while allowing for instructor feedback $[5,10]$.

Health Care Systems and Education Informatics and Technology (Health-IT) is an online course run on the Canvas platform; a cloud-based e-learning management system. Students in this course participated in five interactive discussion forums, completed two exams, submitted one written paper, and one simulated-EHR assignment.

\subsection{Study Sample}

Students in a family nurse practitioner program enrolled in the Health-IT course Fall, 2019 were study participants. At the beginning of the semester, 25 students enrolled but 1 student dropped 4 weeks later. Total 24 students participated until the end of the semester. 


\subsection{Study Steps}

\subsubsection{Step 1: Customizing Scenarios}

We customized 10 scenarios from built-in scenarios in DocuCare suitable for students in a family nurse practitioner program. In other words, all scenarios were modified following a patient visits to a clinic to see a family nurse practitioner. Customized scenarios were displayed for students' use in DocuCare.

\subsubsection{Step 2: Implementing a Simulated HER Assignment in Health-IT Course}

Core concepts of nursing informatics science and practice are summarized in the Data, Information, Knowledge and Wisdom (DIKW) framework [11]. The framework explains how information can be formed based on discrete data from a patient around which nursing knowledge can be synthesized. The appropriate application of nursing knowledge to patient care is known as Wisdom.

This assignment was designed to enhance learning core concepts of nursing informatics (DIKW framework) through hands-on experience. We excluded the Wisdom component to avoid complicated scenario customization in DocuCare. For example, each scenario included vital signs, laboratory data (e.g. CBC, X-ray), and some nursing orders with a brief explanation of the reason for a patient's visit. Students were asked to identify attributes of data and information from DocuCare. They were then asked to document nursing knowledge in DocuCare based on identified data and information.

In the Canvas platform, a detailed instruction of a simulated EHR assignment was posted. An instruction posted includes a short video about steps to follow. Students were given a 2 -week deadline to complete the assignment.

\subsubsection{Step 3: Training Students}

Students were trained on how to use DocuCare (e.g. documenting patient vital signs, ordering labs, writing assessment notes) through a 15 minute-long video instruction before starting the assignment.

\subsubsection{Step 5: Evaluating Nursing Informatics Competency}

After obtaining the university institutional review board approval, an existing survey questionnaire, the Self-Assessment of Informatics Competency Scale for Health Professionals (SICS) [9], was used to collect data at the end of the semester. The SICS tool has strong reliability (Cronbach's alpha $=0.93$ ) and measures three domains of informatics competency: basic computer skills, role, and applied computer skills (clinical informatics).

\section{Results}

One student declined to participate in this study. SICS survey data from 23 students were analyzed utilizing the Shapiro-Wilk test with SPSS version 25. Data showed normal distribution. Table 1 lists the demographic breakdown of participants. 
Table 1. Student characteristics $(\mathrm{N}=23)$

\begin{tabular}{|c|c|c|c|c|c|}
\hline \multicolumn{6}{|c|}{ n (\%) } \\
\hline \multicolumn{2}{|l|}{ Gender } & \multicolumn{2}{|l|}{ Race/Ethnicity } & \multicolumn{2}{|l|}{ Age (years) } \\
\hline Female & $22(95.7)$ & Asian/Pacific Islanders & $0(0)$ & $20-29$ & $7(30.4)$ \\
\hline \multirow[t]{4}{*}{ Male } & $1(4.3)$ & Black, not Hispanic & $1(4.3)$ & $30-39$ & $7(30.4)$ \\
\hline & & Hispanic/Latino & $1(4.3)$ & $40-49$ & $9(39.1)$ \\
\hline & & White, not Hispanic & $21(91.3)$ & 50 or older & $0(0)$ \\
\hline & & Other & $0(0)$ & & \\
\hline Nursing & & Frequency of & & Computer & \\
\hline Experience & & Computer & & Experience & \\
\hline (years) & & Use & & & \\
\hline$<2$ & $0(0)$ & Several times/day & $21(91.3)$ & $<6$ months & $1(4.3)$ \\
\hline $2-5$ & $13(56.5)$ & Once/day & $0(0)$ & $\leq 2$ years & $0(0)$ \\
\hline $6-10$ & $6(26.1)$ & Several times/week & $2(8.7)$ & $>2$ years & $22(95.7)$ \\
\hline$>10$ & $4(17.4)$ & Several times/month & $0(0)$ & & \\
\hline
\end{tabular}

Table 2 shows three domains of self assessed nursing informatics competency level.

Table 2. Self-Assessment of Informatics Competency Scale for health professionals (SICS) (N-23)

\begin{tabular}{ll}
\hline & Average (SD), Range [1-5] \\
\hline SICS & $3.7(0.6)$ \\
Basic Computer Skills & $4.0(0.5)$ \\
Role & $4.5(0.5)$ \\
Applied Computer Skills: Clinical Informatics & $3.4(0.6)$ \\
\hline 1=Not competent, 2=Somewhat competent, 3=Competent, 4=Proficient, 5=Expert
\end{tabular}

\section{Discussion}

Studies indicate that simulation and hands-on experience in online courses could increase students' learning efficiency [5,7]. To increase learning efficiency in an online nursing informatics course, simulated Electronic Medical Records (EHRs) with customized scenarios were successfully implemented and presented to students in a family nurse practitioner program. We hypothesized that students' nursing informatics competency level would be above proficient in all three domains after experiencing simulated EHR assignment.

Study results show that the overall nursing informatics competency level was between competent and proficient (Table 2). In regard to the three individual domains, Basic Computer skills and Role showed above proficient competency levels and Applied Computer Skills (Clinical informatics) was between competent and proficient. The majority of students $(91.3 \%, \mathrm{n}=21)$ indicated that frequency of computer use was several times per day and computer experience was more than 2 years $(95.7 \%, n=22)$. The results clearly support an above proficient level of informatics competency in Basic Computer skills and Role. A little more than half the students $(56.5 \%, \mathrm{n}=13)$ indicated 2-5 years of nursing experience that may have caused below proficient levels of informatics competency in the Applied Computer Skills (Clinical informatics) domain and overall.

There are several limitations of this study. The majority of students were female $(95.7 \% \mathrm{n}=22)$ and white (not Hispanic, 91.3\%, $\mathrm{n}=21)$. Experiencing simulated EHR was offered only once giving little opportunity to measure improvement over time. A greater gender balance and ethnic representation may have altered the results. If this simulated hands-on experience is offered multiple times to students, nursing informatics 
competency level (overall and Applied Computer Skills (Clinical informatics)) may show higher than proficient competency level.

\section{Conclusion}

More nursing courses, including nursing informatics, have been moving to online platforms due to the shortage of nursing faculties and the lack of classrooms. Although online courses are supported by high quality technology, learning efficiency in an online course is subject to criticism. In this small-scale study, simulated hands-on experience was developed and offered to graduate students in a family nurse practitioner program to increase learning efficiency and to measure their nursing informatics competency level.

Although the results found overall nursing informatics competency level fell short of 'Expert', it is a worthy benchmark for how a simulated hands-on assignment impacts nursing informatics competency. Study steps and results could help to develop new and enhanced nursing informatics online courses.

\section{Acknowledgements}

This study is based upon work supported by the Academic Partnerships Faculty Research Grant Program.

\section{References}

[1] Foronda CL, Bauman E. Strategies to incorporate virtual simulation in nurse education. Clinical Simulation in Nursing, 2014. 10(8): p. 412-418.

[2] Voutilainen A, Saaranen T, Sormunen M. Conventional vs. e-learning in nursing education: A systematic review and meta-analysis. Nurse Educ Today, 2017. 50: p. 97-103.

[3] Mannisto M et al. Digital collaborative learning in nursing education: a systematic review. Scand J Caring Sci, 2019.

[4] Xie $\mathrm{H}$ et al. Trends and development in technology-enhanced adaptive/personalized learning: A systematic review of journal publications from 2007 to 2017. Computers \& Education, 2019. 140.

[5] Foronda CL et al. Virtually nursing: Emerging technologies in nursing education. Nurse Educ, 2017. 42(1): p. 14-17.

[6] Verkuyl M et al. Virtual gaming simulation in nursing education: A focus group study. J Nurs Educ, 2017. 56(5): p. 274-280.

[7] Arkorful A, Abaidoo N. The role of e-learning, advantages and disadvantages of its adoption in higher education. International Journal of Instructional Technology and Distance Learning, 2015. 12(1): p. 2942.

[8] March CA et al. Use of electronic health record simulation to understand the accuracy of intern progress notes. J Grad Med Educ, 2016. 8(2): p. 237-40.

[9] Yoon S, Shaffer J, Bakken S. Refining a self-assessment of informatics competency scale using Mokken scaling analysis. Journal of Interprofessional Care, 2015. 29(6): p. 579-586.

[10] Kluwer W. DocuCare overview. [cited 2019 2/18]; Available from: http://thepoint.lww.com/docucare

[11] ANA. Nursing informatics: Scope and standards of practice. 2008, Springfield, MD: nursesbooks.org. 